\title{
Altered neuronal architecture and plasticity in the visual cortex of adult MMP-3-deficient mice
}

\author{
Jeroen Aerts $\cdot$ Julie Nys $\cdot$ Lieve Moons $\cdot$ \\ Tjing-Tjing $\mathrm{Hu} \cdot$ Lutgarde Arckens
}

Received: 12 February 2014 / Accepted: 5 June 2014

(C) Springer-Verlag Berlin Heidelberg 2014

\begin{abstract}
Matrix metalloproteinases (MMPs) are $\mathrm{Zn}^{2+}$ dependent endopeptidases considered to be essential for normal brain development and neuroplasticity by modulating extracellular matrix proteins, receptors, adhesion molecules, growth factors and cytoskeletal proteins. Specifically, MMP-3 has recently been implicated in synaptic plasticity, hippocampus-dependent learning and neuronal development and migration in the cerebellum. However, the function(s) of this enzyme in the neocortex is understudied. Therefore, we explored the phenotypical characteristics of the neuronal architecture and the capacity for experience-dependent cortical plasticity in the visual cortex of adult MMP-3-deficient (MMP-3 ${ }^{-1-}$ ) mice. Golgi-Cox stainings revealed a significant reduction in apical dendritic length and an increased number of apical obliques for layer $\mathrm{V}$ pyramidal neurons in the visual cortex of adult MMP$3^{-I-}$ mice compared to wild-type (WT) animals. In addition, a significant upregulation of both phosphorylated and non-phosphorylated neurofilament protein (NF)-high, phosphorylated NF-medium, NF-low and $\alpha$-internexin was detected in the visual cortex of MMP- $3^{-1-}$ mice. To assess the effect of MMP-3 deficiency on cortical plasticity, we monocularly enucleated adult MMP- $3^{-1-}$ mice and analyzed the reactivation of the contralateral visual cortex 7 weeks post-enucleation. In contrast to previous results in
\end{abstract}

J. Aerts $\cdot$ J. Nys $\cdot$ T.-T. Hu $\cdot$ L. Arckens $(\bowtie)$

Laboratory of Neuroplasticity and Neuroproteomics,

KU Leuven, Naamsestraat 59, 3000, Leuven, Belgium

e-mail: lut.arckens@bio.kuleuven.be

\section{J. Aerts}

e-mail: jeroen.aerts@bio.kuleuven.be

L. Moons - T.-T. Hu

Laboratory of Neural Circuit Development and Regeneration,

KU Leuven, Naamsestraat 61, 3000 Leuven, Belgium
C57B1/6J adult mice, activity remained confined to the binocular zone and did not expand into the monocular regions indicative for an aberrant open-eye potentiation. Permanent hypoactivity in the monocular cortex lateral and medial to V1 also indicated a lack of cross-modal plasticity. These observations demonstrate that genetic inactivation of MMP-3 has profound effects on the structural integrity and plasticity response of the visual cortex of adult mice.

Keywords Matrix metalloproteinase - Golgi-Cox . Apical dendrite $\cdot$ Neurofilament $\cdot$ Monocular enucleation . Multimodal

\section{Introduction}

The capacity of the mammalian brain to change its functional and anatomical organization based on sensory experience is defined as neuroplasticity. To ensure a correct development of sensory systems, genetically determined molecular programs control the formation of connections that are further sculpted by neural activity and are able to adapt after injury or sensory manipulation through experience-dependent plasticity (Penn and Shatz 1999; Spolidoro et al. 2008). The visual system is the prime model for studying brain plasticity, including changes in deprived as well as non-deprived areas in response to sensory impairment, referred to as cross-modal plasticity. In the visual cortex of adult mice, we recently revealed a potential for cross-modal plasticity following monocular enucleation (ME) (Van Brussel et al. 2011; Nys et al. 2014). We provided evidence for an extensive reactivation of the visual cortex within 7 weeks post-ME. This reactivation was driven by an initial open-eye potentiation followed by 
cross-modally driven plasticity in the medial and lateral monocular zones starting from adjacent non-visual cortices around 3 weeks post-ME (Van Brussel et al. 2011). However, the molecular determinants regulating these two distinct plasticity processes still remain unclear. In that regard, matrix metalloproteinases (MMPs), $\mathrm{Zn}^{2+}$-dependent endopeptidases that modulate extracellular matrix proteins, chemokines, cytokines, growth factors, receptors and a range of intracellular substrates have over the years been identified as major regulators of normal brain development and neuroplasticity (Yong 2005; Ethell and Ethell 2007; Cauwe and Opdenakker 2010; Mannello and Medda 2012). Indeed, it is well established that MMPs are necessary for proper axon guidance and elongation (Gonthier et al. 2006; Oliveira-Silva et al. 2007), neurite remodeling (Hinkle et al. 2006; Yasunaga et al. 2010; Van Hove et al. 2011; Fujioka et al. 2012), dendritic spine dynamics and elongation (Szklarczyk et al. 2002; Hinkle et al. 2006; Michaluk et al. 2011), synaptic plasticity (Dziembowska and Wlodarczyk 2012; Fujioka et al. 2012) and learning and memory (Meighan et al. 2006; Nagy et al. 2006; Wright et al. 2009). Several MMPs, including MMP-3, are expressed in the cortex both under normal and pathological conditions such as stroke (Solé et al. 2004; Gonthier et al. 2006, 2009; Milward et al. 2007). Moreover, it has been shown that MMP-3 is necessary for proper cortical axon extension and guidance through interaction with semaphorin-3A and -3C (Gonthier et al. 2006). MMP-3 is able to cleave and activate several other MMPs (Ogata et al. 1992; Murphy et al. 1999) including MMP-9, which is a major regulator of dendritic spine dynamics, and late-phase LTP (Szklarczyk et al. 2002; Michaluk et al. 2009, 2011). Recently, Spolidoro et al. (2012) uncovered a role for MMPs in critical period plasticity of the visual cortex in monocular-deprived (MD) rats. Infusion of a broad-spectrum MMP inhibitor prevented both the potentiation of the open-eye response and the increase in spine density on layer II-III pyramidal neurons after MD (Spolidoro et al. 2012). However, studies focusing on MMP-3 in visual cortex plasticity are lacking. Here we investigated the role of this specific endopeptidase in ME-induced plasticity of the visual cortex using adult MMP-3-deficient (MMP$3^{-1-}$ ) mice. An assessment of MMP-3 deficiency on the structure and functionality of the adult visual cortex is crucial to understand plasticity-related manipulations in these mice.

Here, we describe a phenotypical characterization of the visual cortex of MMP- $3^{-1-}$ mice using Golgi-Cox staining, revealing an aberrant neuronal morphology. Western analysis of cytoskeletal proteins disclosed a differential composition of neurofilament proteins complementing these findings. Finally, to assess these impairments at a functional level we performed $\mathrm{ME}$ to probe for an involvement of MMP-3 in experience-dependent cortical plasticity.

\section{Materials and methods}

Animals

All experiments were performed in adult (120 days old) wild-type (WT) and MMP-3 deficient (MMP- $3^{-/-}$) mice with a similar genetic background (50\% B16 × $25 \%$ B10 $\times 25 \%$ RIII) (Mudgett, Merck Labs) which were housed under standard laboratory conditions under an 11/13-h dark/light cycle with food and water available ad libitum. All experiments were approved by the Ethical Research Committee of KU Leuven and were in strict accordance with the European Communities Council Directive of 22 September 2010 (2010/63/EU) and with the Belgian legislation (KB of 29 May 2013). Every possible effort was made to minimize animal suffering and to reduce the number of animals.

\section{Golgi-Cox staining}

WT $(n=3)$ and MMP- $3^{-1-}(n=3)$ mice received an intraperitoneal injection of sodium pentobarbital (Nembutal, $600 \mathrm{mg} / \mathrm{kg}$, Ceva Sante Animale) before being perfused transcardially with $1 \%$ paraformaldehyde (PFA, Sigma-Aldrich, St. Louis, MO) in 0.15 M phosphate-buffered saline (PBS, $\mathrm{pH} 7.42$ ) at $37{ }^{\circ} \mathrm{C}$. Brains were dissected and post-fixated in $4 \%$ PFA in PBS for $1 \mathrm{~h}$ after which they were impregnated with the Golgi-staining solution (FD Rapid GolgiStain kit, FD Neurotechnologies Inc., USA) for 12-14 days in complete darkness. The impregnated brains were further processed using a vibratome (Leica VT1000S, Leica Microsystems GmbH, Wetzlar, Germany) into $80-\mu \mathrm{m}$-thick coronal sections. These sections were stained in developing solution (FD Rapid GolgiStain Kit), placed on glass slides and air-dried for 3 days before being dehydrated and coverslipped for imaging with bright field microscopy (Zeiss Axio Imager Z.1, software program Axiovision Rel. 4.6, Carl Zeiss Benelux).

\section{Morphometric quantification}

The dendritic composition of layer $\mathrm{V}$ pyramidal cells ( $n=12-15$ /animal) exhibiting complete Golgi impregnation was manually traced on flattened Z-stack images using the brush tool in Adobe Photoshop CS5 and a pen tablet (Wacom Co., Ltd.). To exclude possible misinterpretations of branching patterns, the tracings done on the flattened images were checked against the original Z-stack data. For each extracted neuron the apical shaft length, mean oblique 
length, number of obliques, number of branching points and spine density on the apical shaft were measured using Axiovision Rel. 4.6 (Carl Zeiss, Benelux). The spine density was determined at a final magnification of $\times 1000$ by manually counting the spines on two consecutive $25 \mu \mathrm{m}$ segments on the apical shaft of each neuron starting at a distance of $50 \mu \mathrm{m}$ away from the cell body. The dendritic diameter was noted every $25 \mu \mathrm{m}$. For each segment the length of up to ten spines was measured and only spines with a clear connection to the apical shaft were included. For each condition, the data were presented as the mean \pm standard error of the mean (SEM).

\section{Western blotting}

For each mouse (WT, $n=6$; $\mathrm{MMP}^{-1-}, n=6$ ), the visual cortex was collected from $100-\mu \mathrm{m}$-thick coronal cryosections spanning Bregma levels -2.00 to -4.60 . Proteins were extracted with a lysis buffer [50 mM Tris, 5 mM EDTA, $1 \%$ Triton X-100, 1 mM DTT, pH 7.4 and complete protease inhibitor cocktail (Roche Diagnostics Ltd, Mannheim, Germany)] and the samples were centrifuged $(8,000 \times g)$ for $5 \mathrm{~min}$ at $4{ }^{\circ} \mathrm{C}$. The supernatant was isolated and the total protein concentration was determined by means of a Qubit ${ }^{\mathrm{TM}}$ fluorometer (Invitrogen, Merelbeke, Belgium). Samples were stored at $-80{ }^{\circ} \mathrm{C}$. For immunodetection of non-phosphorylated neurofilamenthigh (NF-H), phosphorylated neurofilament-high/-medium (pNF-H/-M), neurofilament-low (NF-L) and $\alpha$-internexin (NF-66), equal amounts of protein $(10 \mu \mathrm{g})$ were loaded onto 4-12\% Bis-Tris Midi gels (NuPAGE Novex, Invitrogen) and transferred to a polyvinylidene fluoride (PVDF) (NF-L) or nitrocellulose (NF-H, pNF-H/M and NF-66) membrane. Overnight incubation with the monoclonal antibody SMI-32R (1:500, Covance Research Products, USA; Sternberger and Sternberger 1983), SMI-31R (1:1,000, Covance Research Products, USA; Sternberger and Sternberger 1983), anti-NF-L (1:5,000, Mab1615, Merck Millipore, Germany) and anti-NF-66 (1:5,000, NBP1-49175, Novus Biologicals, USA) was followed by 30 min incubation with HRP-labeled secondary antibodies (1:50,000, Dako, Denmark). The immunoreactive bands were visualized using a luminol-based enhanced chemiluminescent kit (SuperSignal West Dura, Thermo Scientific, USA). In order to correct for inter-gel variability and to normalize the concentration of the specific detected proteins to the total amount of protein present, we performed a total protein stain (TPS) prior to immunodetection with LavaPurple (Gelcompany, USA) according to manufacturer's instructions. After the staining, dry blots were scanned with a ChemiDocTM MP Imaging System (BioRad Laboratories, USA).
The protein bands were semi-quantitatively evaluated by densitometry (Image Lab 4.1, Bio-Rad Laboratories, USA). First, to account for inter-gel variability including loading differences, incomplete transfer or position on the blot, a TPS was employed rather than the use of a single reference protein (Aldridge et al. 2008; Hu et al. 2011). For each protein of interest, the optical density value per mouse was normalized to its corresponding TPS. Also, to compare samples between different gels, normalized data were expressed relative to the reference sample, i.e., a pool of all samples.

Monocular enucleation and in situ hybridization

Monocular enucleation of the mice ( $n=4 /$ condition) was performed as previously described (Van Brussel et al. 2009, 2011; Nys et al. 2014; Aerts et al. 2014). Briefly, under anesthesia by intraperitoneal injection of a mixture of ketamine hydrochloride $(75 \mathrm{mg} / \mathrm{kg}$, Dechra Veterinary Producs, Eurovet) and medetomidine hydrochloride (1 mg/ $\mathrm{kg}$, Orion Corporation, Janssen Animal Health) in saline, the right eye was carefully removed and if needed, the orbit was filled with hemostatic cotton wool (Qualiphar, Bornem, Belgium). After injection with atipamezol hydrochloride $(1 \mathrm{mg} / \mathrm{kg}$, Orion Corporation, Elanco Animal Health) to reverse anesthesia, the animals were allowed to recover on a heating pad. They were all administered $0.05 \mathrm{ml}$ of antibiotics (Kefzol, $1 \mathrm{~g}$ Natrii cefazolin and $15 \mathrm{mg}$ Lidocaini hydrochloridum anhydricum in $4 \mathrm{ml}$ $0.9 \% \mathrm{NaCl}$, Eurocept Pharmaceuticals) intramuscularly to prevent post-surgical infections. After the enucleation procedure, mice were again housed under the same normal light conditions in standard cages for a survival period of 7 weeks. Prior to sacrifice, the animals underwent an overnight dark exposure followed by $45 \mathrm{~min}$ of bright light to obtain an optimal visually evoked zif268 expression (Worley et al. 1991; Kaczmarek and Chaudhuri 1997; Arckens et al. 2000; Zangenehpour and Chaudhuri 2002; Van der Gucht et al. 2007).

For in situ hybridization experiments, all mice received an overdose of sodium pentobarbital (Nembutal, $600 \mathrm{mg}$ / $\mathrm{kg}$, Ceva Sante Animale) by intraperitoneal injection prior to sacrifice by cervical dislocation. The brains were rapidly removed and immediately frozen in 2-methylbutane (Merck, Overijse, Belgium) at a temperature of $-40{ }^{\circ} \mathrm{C}$ and stored at $-80{ }^{\circ} \mathrm{C}$ until sectioning. $25-\mu \mathrm{m}$-thick sections were prepared on a cryostat (Microm HM 500 OM, Walldorf, Germany), mounted on $0.1 \%$ poly-L-lysine (Sigma-Aldrich, St. Louis, MO)-coated slides and stored at $-20{ }^{\circ} \mathrm{C}$ until further processing.

In situ hybridization was performed with a mouse-specific synthetic oligonucleotide probe (Eurogentec, Seraing, 
Belgium) with sequence $5^{\prime}$-ccgttgctcagcagcatcatctcctccagtttggggtagttgtcc- $3^{\prime}$ for zif268. This oligonucleotide probe has been used successfully for the analysis of zif 268 mRNA expression in the mouse brain in previous publications (Van Brussel et al. 2011; Woolley et al. 2013; Nys et al. 2014). As described earlier (Arckens et al. 1995; Cnops et al. 2007), each probe was $3^{\prime}$-end labeled with ${ }^{33} \mathrm{P}$ dATP using terminal deoxynucleotidyl transferase (Invitrogen, Paisley, UK). Unincorporated nucleotides were separated from the labeled probe with miniQuick SpinTM Oligo Columns (Roche Diagnostics, Brussels, Belgium). Series of cryostat sections (every $50 \mu \mathrm{m}$ ) were fixed, dehydrated and delipidated. The radioactively labeled probe was added to a hybridization cocktail [50\% (vol/ vol) formamide, $4 \times$ standard saline sodium citrate buffer, $1 \times$ Denhardt's solution, $10 \%$ (wt/vol) dextran sulfate, $100 \mu \mathrm{g} / \mathrm{ml}$ herring sperm DNA, $250 \mu \mathrm{g} / \mathrm{ml} \mathrm{tRNA}, 60 \mathrm{mM}$ dithiothreitol, $1 \%$ (wt/vol) $N$-lauroyl sarcosine, $20 \mathrm{mM}$ $\mathrm{NaHPO}_{4}, \mathrm{pH}$ 7.4] and applied to the cryostat sections $\left(10^{6} \mathrm{cpm} / \mathrm{section}\right)$ for an overnight incubation at $37{ }^{\circ} \mathrm{C}$ in a humid chamber. The following day, sections were rinsed in $1 \times$ standard saline sodium citrate buffer at a temperature of $42{ }^{\circ} \mathrm{C}$, dehydrated, air-dried and exposed to an autoradiographic film (Biomax MR, Kodak, Zaventem, Belgium). Films were developed in Kodak D19 developing solution after 7 days and fixation was performed in Rapid fixer (Ilford Hypam, Kodak).

For each mouse, autoradiographic images from three adjacent sections were scanned at 1,200 dpi (CanoScan LIDE 600F, Canon, USA). Pseudo-color maps were generated with a custom-made MATLAB script (MATLAB R2008b, The MathWorks Inc., Natick, MA) and represent a false coloring of the gray values: a low gray value is represented in black/green, a high gray value in white/yellow, indicating a low signal response or a high signal response, respectively. This is done in accordance with a gray scale ranging from black (0) to white (255).

\section{Histology}

Histology was performed on each section to aid interpretation of the activity patterns obtained by in situ hybridization. The cryostat sections for zif268 were therefore Nissl-counterstained (Cresyl violet $1 \%$, Fluka Chemika, Sigma-Aldrich) according to standard procedures. Comparisons were made to a stereotaxic mouse brain atlas (Franklin and Paxinos 2008). Images of the stained coronal sections were obtained with a light microscope (Zeiss Axio Imager Z.1) equipped with an AxioCam MRm camera $(1388 \times 1040$ pixels $)$ using the software program Axiovision Rel. 4.6 (Carl Zeiss Benelux).
Localization of visual areal boundaries with Nissl patterns

To anatomically delineate the areal borders of the different visual subdivisions a comparison was made with Nisslcounterstained sections as described previously by Van Brussel et al. (2009, 2011) and Nys et al. (2014). All topographic denominations were adopted from these papers. Concurrently, we applied the mapping of functional subdivisions of the visual cortex as located by Van Brussel et al. (2009) where the eye-specific inputs were identified using enucleation of one eye combined with stimulation of the remaining eye. Combined, these methods allowed for the generation of animal-specific coronal atlases of visual cortex and thus provided a reliable guide for the interpretation of zif 268 in situ hybridization results. In all figures, large arrowheads indicate the total extent of the visual cortex while small arrowheads indicate areal borders. We always distinguished 5 regions from medial to lateral: medial extrastriate cortex (V2M), primary visual cortex (V1), which was further subdivided in the monocular (V1m) and the binocular (V1b) part, and lateral extrastriate cortex (V2L), which was also subdivided into a monocular (V2Lm) and a binocular (V2Lb) region. In relation to functional inputs, we defined the V1-V2L border as the central binocular zone $(\mathrm{Bz})$, a large part of V2M and V1m as the medial monocular zone $(\mathrm{Mmz})$, and V2Lm as the lateral monocular zone (Lmz). In Figs. 4 and 5, the location of the binocular zone has been indicated with the gray letter b. Adjoining monocularly driven parts of $\mathrm{V} 1$ and $\mathrm{V} 2 \mathrm{~L}$ are marked with a gray letter $\mathrm{m}$.

\section{Quantitative analysis of ISH results}

As described before (Nys et al. 2014), optical density values (mean gray value per pixel) from the autoradiograms of different experimental and control groups were quantified using a custom-made MATLAB script (MATLAB R2008b, The MathWorks Inc., Natick, MA). For each condition at least three mice were included and for each mouse three 25 - $\mu \mathrm{m}$-thick sections were selected between -3.00 and $-4.00 \mathrm{~mm}$ relative to Bregma (Franklin and Paxinos 2008). In order to demarcate the region of interest in the left hemisphere, we determined the top edge of the cortex, the border between the granular layer IV and infragranular layer V and the boundary where layer VI meets the white matter. These layer-related borders were computed by a contour smoothing algorithm based on the Gaussian weighted least squares fit (Birdal, 2011) from manually drawn lines on the autoradiogram. The different areal and functional boundaries as derived from Nissl patterns were subsequently registered to the curvature of 
the top and bottom boundaries. Next, the delineated region of interest was equally divided into 24 segments (D'Errico 2012) creating two lattices of 24 quadrangles, corresponding to the upper (LII-IV) and lower (LV-VI) layers. To compensate for possible variation in brain size and morphology, we translated the lattice on each autoradiogram over the cortical curvature, fixing the border of a specific segment to an areal border (border segment 19/20 is area border $\mathrm{V} 1 \mathrm{~m} / \mathrm{V} 2 \mathrm{M}$ ). For each segment created this way, the relative optical density was calculated as the mean gray value of all pixels within this quadrangle normalized to the mean gray value of a square measured in the thalamus (a defined region with no zif268 expression above background). This procedure was required to compare autoradiograms across experiments (Van Brussel et al. 2011; Paulussen et al. 2011). Relative molecular activity was expressed in percentages based on the following formula: $[1$ - (cortical zif268/thalamic background)] $\times 100$. We compared zif268 expression between different experimental and control groups for upper and lower layers of the visual cortex separately. Furthermore, relative expression patterns were assessed along the anatomically defined visual subdivisions as well as in the functionally distinct areas consisting of the central binocular zone and two flanking monocular zones.

\section{Statistics}

All Western blot data and data of the Golgi-Cox staining except for the spine length distribution were presented as mean \pm SEM. A normal distribution was verified using the Kolmogorov-Smirnov test and parallel equal variance between groups was tested. If the test requirements were fulfilled, an unpaired Student's $t$ test for pairwise comparison was used $(* P<0.05, * * P<0.01, * * * P<0.001)$. When criteria for this parametrical test were not fulfilled, a Mann-Whitney U rank-sum test for pairwise comparison of independent samples was applied $(* P<0.05$, $* * P<0.01$, ***P $<0.001)$. For comparing the distribution of spine length across groups, a Chi square analysis was performed and data were presented as the percentage of total spine number per spine length interval.

To compare the ISH results for each condition, the data of relative optical densities were presented as mean \pm SEM. A normal distribution was verified using the KolmogorovSmirnov test and parallel equal variance between groups was tested. If the test requirements were fulfilled, for the ISH data, a two-way ANOVA was used with factors zone (functional: binocular, medial monocular or lateral monocular zone) and genotype (WT or MMP- $3^{-1-}$ ) or deprivation (control of 7wME) to test for ME-specific changes in zif 268 expression. Fisher's LSD post hoc tests were used for pairwise comparisons and a probability level of $<0.05$ ( $\alpha$-level was set to 0.05$)$ was accepted as statistically significant $(* P<0.05, * * P<0.01, * * * P<0.001)$. When criteria for this parametrical test were not fulfilled, a non-parametrical Kruskal-Wallis analysis with a Mann-Whitney U rank-sum test for pairwise comparison of independent samples was applied. When no interaction between the two factors studied was observed, a one-way ANOVA with an unpaired Student $t$ test for pairwise comparison was used $(* P<0.05$, $* * P<0.01, * * * P<0.001)$. Statistical analyses were performed using SigmaStat 3.1 (SYSTAT software).

\section{Results}

Truncated neuronal morphology and impaired translaminar projections in the visual cortex of MMP-3deficient mice

Golgi-Cox staining revealed normal vertical projections across all cortical layers in V1 of WT mice. In contrast, MMP- $3^{-/-}$mice displayed an apparent, truncated translaminar organization (Fig. 1a, b). To address this anatomical feature in more detail, we analyzed layer-specific pyramidal neurons, since they are typically characterized by long apical dendrites supporting the vertical oriented appearance of the stained cortex. Layer $\mathrm{V}$ pyramidal cells of MMP- $3^{-1-}$ mice displayed a significant reduction $(P<0.001)$ in the length of the apical shaft (Fig. 2a-c) and a comparable number of apical branches called obliques $(P=0.666)$, together resulting in a higher density of apical obliques (\# apical obliques/apical shaft length, $P<0.001$ ) compared with WT mice (Fig. 2d, e). No differences between the two genotypes concerning mean oblique length $(P=0.490)$ or branching complexity (mean \# branch points per neuron, $P=0.298$ ) were observed (Fig. 2f, g). These measurements indicate that MMP- $3^{-1-}$ mice have a shorter apical shaft with more apical obliques per unit of length. Spine density on the apical shaft was the same in both genotypes $(P=0.893)$ whereas the distribution of spine length showed significantly shorter spines (Chi square $=10.701, d f=3, P=0.013$ ) in MMP$3^{-1-}$ mice compared with WT (Fig. $2 \mathrm{~h}-\mathrm{j}$ ). These results indicate a higher prevalence of shorter, more mature spines in the cortex of MMP- $3^{-1-}$ mice. No differences in soma size were observed. Dendritic diameter did not differ in each measured segment so no correction factor for spine density was employed (Irwin et al. 2002).

Cytoskeletal protein anomalies in the visual cortex as a result of MMP-3 deficiency

To corroborate the truncated neuronal morphology in the MMP- $3^{-/-}$mice on a molecular level, we compared the 
Fig. 1 Representative bright field images of Golgi-Coxstained primary visual cortex of WT (a) and MMP- $3^{-1-}$ (b) mice. A perturbed translaminar organization characterizes the visual cortex of MMP- $3^{-1-}$ mice. Scale bars $150 \mu \mathrm{m}$ a

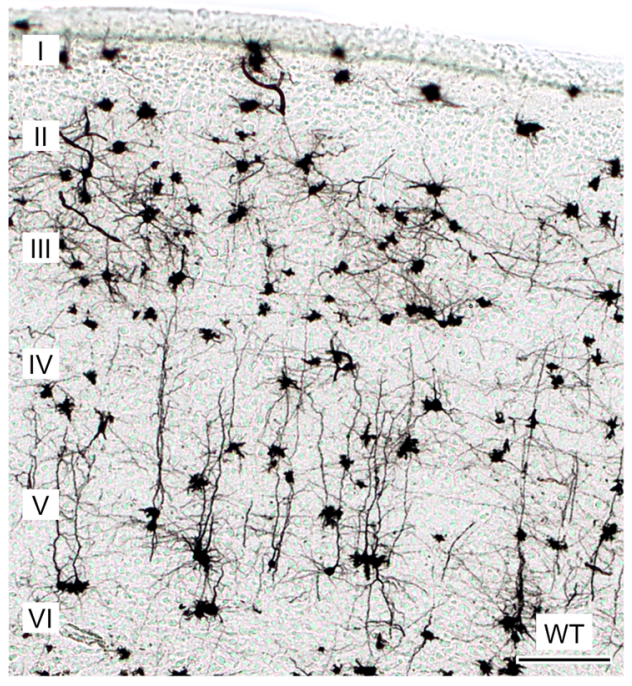

b

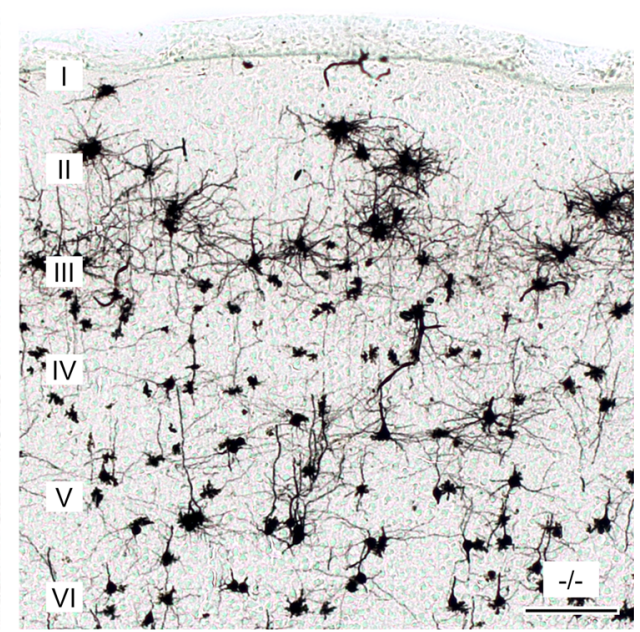

expression levels of different neurofilament proteins in cortices of both genotypes using Western analysis since they constitute the major components of the neuronal cytoskeleton. All analyzed neurofilament proteins (NF) were found to be significantly upregulated in the visual cortex of MMP-3 ${ }^{-l-}$ mice [Fig. 3a-e: non-phosphorylated neurofilament-high $(\mathrm{NF}-\mathrm{H}), P=0.026$, ratio $=1.9 ;$ phosphorylated neurofilament-high (pNF-H), $P=0.011$, ratio $=2.2$; phosphorylated neurofilamentmedium (pNF-M), $P=0.002$, ratio $=3.0$; neurofilamentlow (NF-L), $P<0.001$, ratio $=5.9$ and $\alpha$-internexin $(\mathrm{NF}-$ 66), $P<0.001$, ratio $=2.3$ ]. These results are indicative for an altered neurofilament protein subunit composition and phosphorylation state.

An aberrant visual and cross-modal response to monocular enucleation in MMP-3-deficient mice

In order to assess the response of the visual cortex to ME as a plasticity readout, we performed radioactive in situ hybridization (ISH) for the activity marker gene zif286, as a reliable reporter for light-induced neural activity (Van Brussel et al. 2009, 2011; Nys et al. 2014). ME is a useful model to investigate not only open-eye potentiation (unimodal) but also the cross-modal component of visual cortical plasticity in the mouse (Van Brussel et al. 2011; Nys et al. 2014). Here we applied the same deprivation protocol to WT and MMP- $3^{-/-}$mice to assess the functional outcome of $\mathrm{ME}$ in the context of drastically altered neuronal architecture in $\mathrm{MMP}-3^{-/-}$mice. To exclude possible intrinsic effects of MMP-3 deficiency on visually evoked zif268 expression, we compared the activity profiles of WT control and $\mathrm{MMP}-3^{-1-}$ control mice. No significant differences were found between these two conditions (data not shown), suggesting MMP-3 deficiency itself has no apparent effect on zif268 expression in the visual cortex. Furthermore, it is known that variation in the genetic background affects the capacity for ocular dominance (OD) plasticity in mice (Heimel et al. 2008) and normal adult C57B1/6 J mice display an extensive reactivation along the full extent of the visual cortex within 7 weeks of ME. Hence, we tested whether the genetic background of the WT mice influenced the reactivation pattern 7 weeks postME by comparing age-matched WT mice versus 7 weeks enucleated littermates (Fig. 4a, b). Only the infragranular layers of the medial monocular zone (Mmz: V1m and $\mathrm{V} 2 \mathrm{M}$ ) of the enucleated mice (WT 7wME) showed a significant reduction (Fig. 4d Mmz: $P=0.009$; Fig. 4c Mmz: $P=0.057)$ in zif268 expression compared to the agematched controls (WT control). Yet the binocular zone (Bz: V1b and V2Lb) and lateral monocular visual cortex (Lmz: V2Lm) exhibited no difference in zif268 expression between conditions (Fig. 4c, Bz: $P=0.715$, Lmz: $P=0.523$; Fig. 4d, Bz: $P=0.495$, Lmz: $P=0.886$ ). These results are very comparable to previous observations in C57Bl/6 J mice (Van Brussel et al. 2011; Nys et al. 2014), ruling out a clear effect of the WT genetic background on ME-induced cortical plasticity.

Next, the zif268 expression in the visual cortex of WT $7 \mathrm{wME}$ was compared to that of $\mathrm{MMP}-3^{-1-} 7 \mathrm{wME}$ to primarily determine the effect of MMP-3 deficiency on cross-modal plasticity (Fig. 5a, b). A massive decrease in zif268 expression in the two monocular zones across all layers (Fig. 5c, Lmz: $P=0.012$; Mmz: $P<0.001$; Fig. 5d, Lmz: $P=0.003$; Mmz: $P<0.001)$ was observed in $\mathrm{MMP}-3^{-1-} 7 \mathrm{wME}$ mice compared to WT $7 \mathrm{wME}$. The 
Fig. 2 Morphological analysis of layer $\mathrm{V}$ pyramidal neurons in the visual cortex of WT and MMP-3 $3^{-/-}$mice. a-b

Representative traced pyramidal neurons of WT and MMP- $3^{-1-}$ mice. Scale bars $20 \mu \mathrm{m}$.

Morphometric evaluation of the apical shaft length (c), absolute number of obliques (d), relative number of obliques (e), mean oblique length (f) and number of apical branch points

(g) evidence a significant shorter apical dendrite and higher density of apical obliques in MMP- $3^{-1-}$ mice. Values in c-g represent mean $\pm \mathrm{SEM}$.

Student's $t$ test: *** $P<0.001$ (c) and Mann-Whitney U test *** $P<0.001$ (e).

h Representative Golgi-Coxstained dendritic spines on the apical shaft. Final

magnification: $\times 1000$. Scale bars $5 \mu \mathrm{m}$. i Dendritic spine density is not altered by MMP-3 deficiency. j Frequency distribution of dendritic spine length measured from 50 to $100 \mu \mathrm{m}$ from the soma indicates a higher abundance of shorter spines in MMP- $3^{-1-}$ mice (Chi square $=10.701, d f=3$, $P=0.013$ )
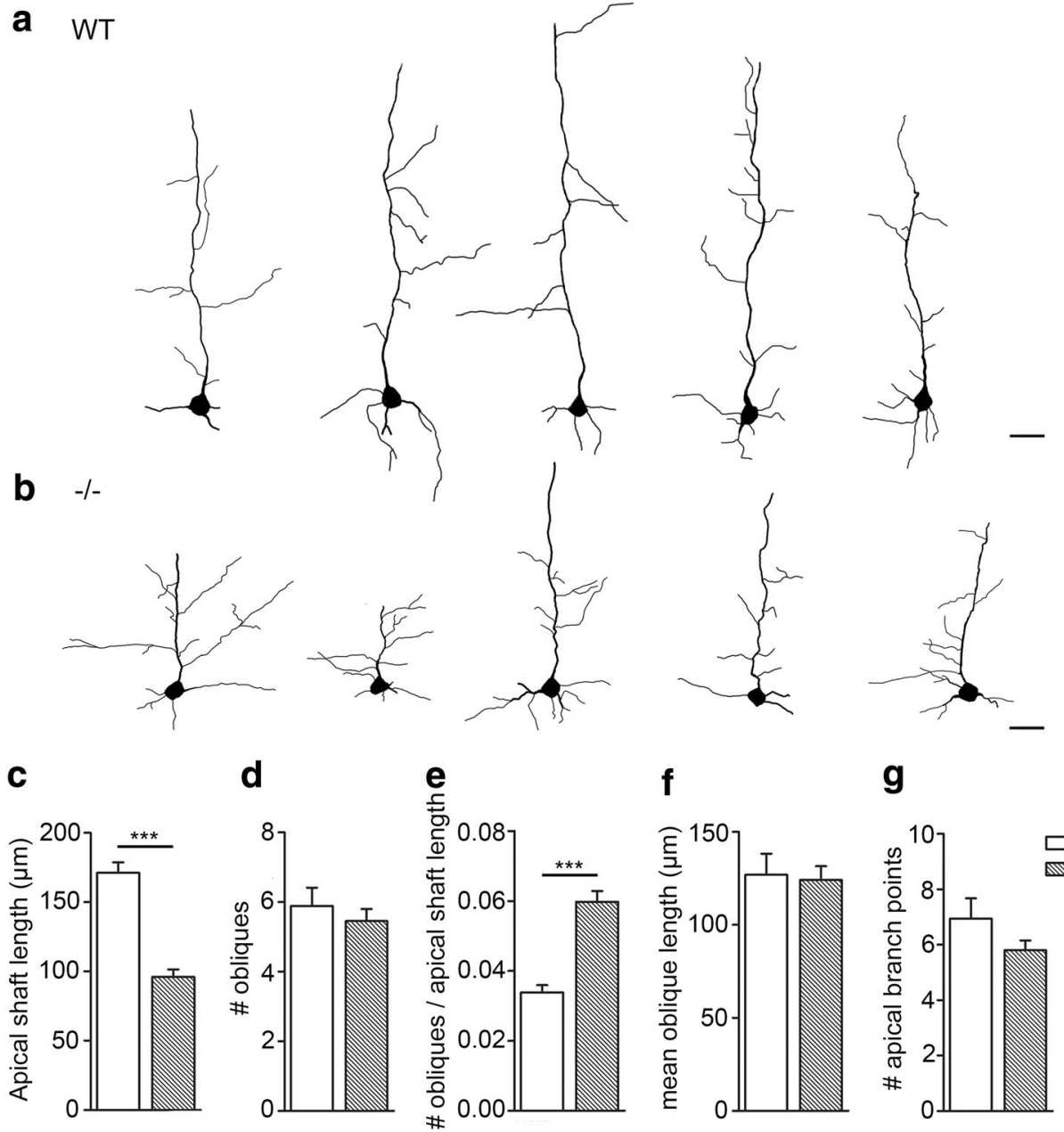

$\mathbf{f}$
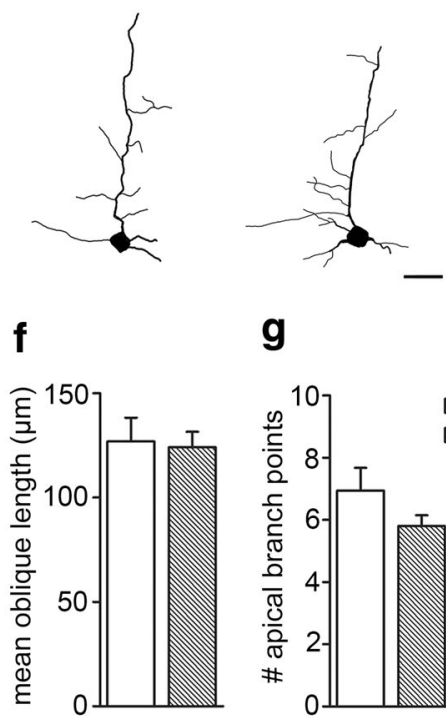

g

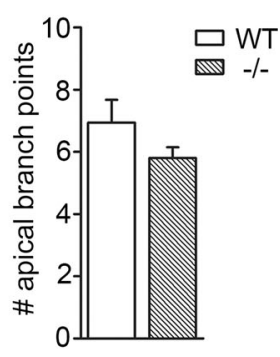

h
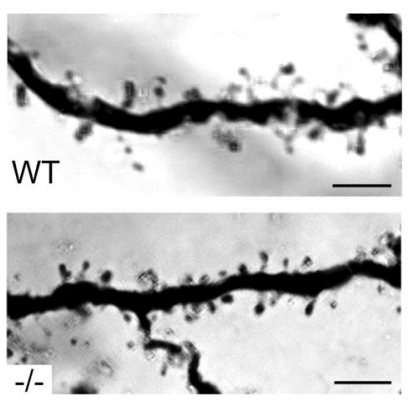
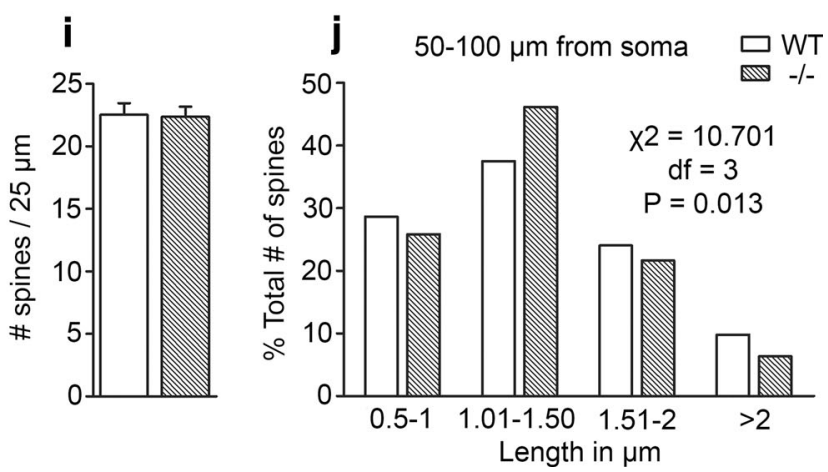

hypoactivity in response to ME was mostly located in monocular driven areas since the relative neural activity remained confined to the $\mathrm{Bz}$ (Fig. 5b). The zif268 expression in the $\mathrm{Bz}$ was only significantly different in the infragranular layers (Fig. 5d, Bz: $P=0.007$ ) and not in the supragranular layers (Fig. 5c, Bz: $P=0.072$ ). Taken together, these results indicate perturbed cross-modal plasticity and open-eye potentiation in the visual cortex of adult $\mathrm{MMP}-3^{-/-}$mice.

\section{Discussion}

Linking MMPs to dendrite arborization

Within this study we demonstrate that genetic inactivation of MMP-3 has profound effects on the structural and functional integrity of the visual cortex in adult mice. In fact, images of Golgi-stained cortices could be assigned to either originating from WT or MMP- $3^{-1-}$ mice, based on 
Fig. 3 Analysis of different neurofilament protein levels in the visual cortex of WT and MMP- $3^{-/-}$mice. All analyzed neurofilament proteins are significantly upregulated in MMP- $3^{-1-}$ mice: a nonphosphorylated neurofilamenthigh (NF-H), $P=0.026$;

b phosphorylated neurofilament-high (pNF-H), $P=0.011 ;$ c phosphorylated neurofilament-medium (pNFM), $P=0.002$;

d neurofilament-low (NF-L), $P<0.001$ and $\mathbf{e} \alpha$-internexin (NF-66), $P<0.001$ with $* P<0.05, * * P<0.01$, $* * * P<0.001$. Above each graph representative bands and their corresponding molecular weight are shown. Values in a-e represent mean \pm SEM

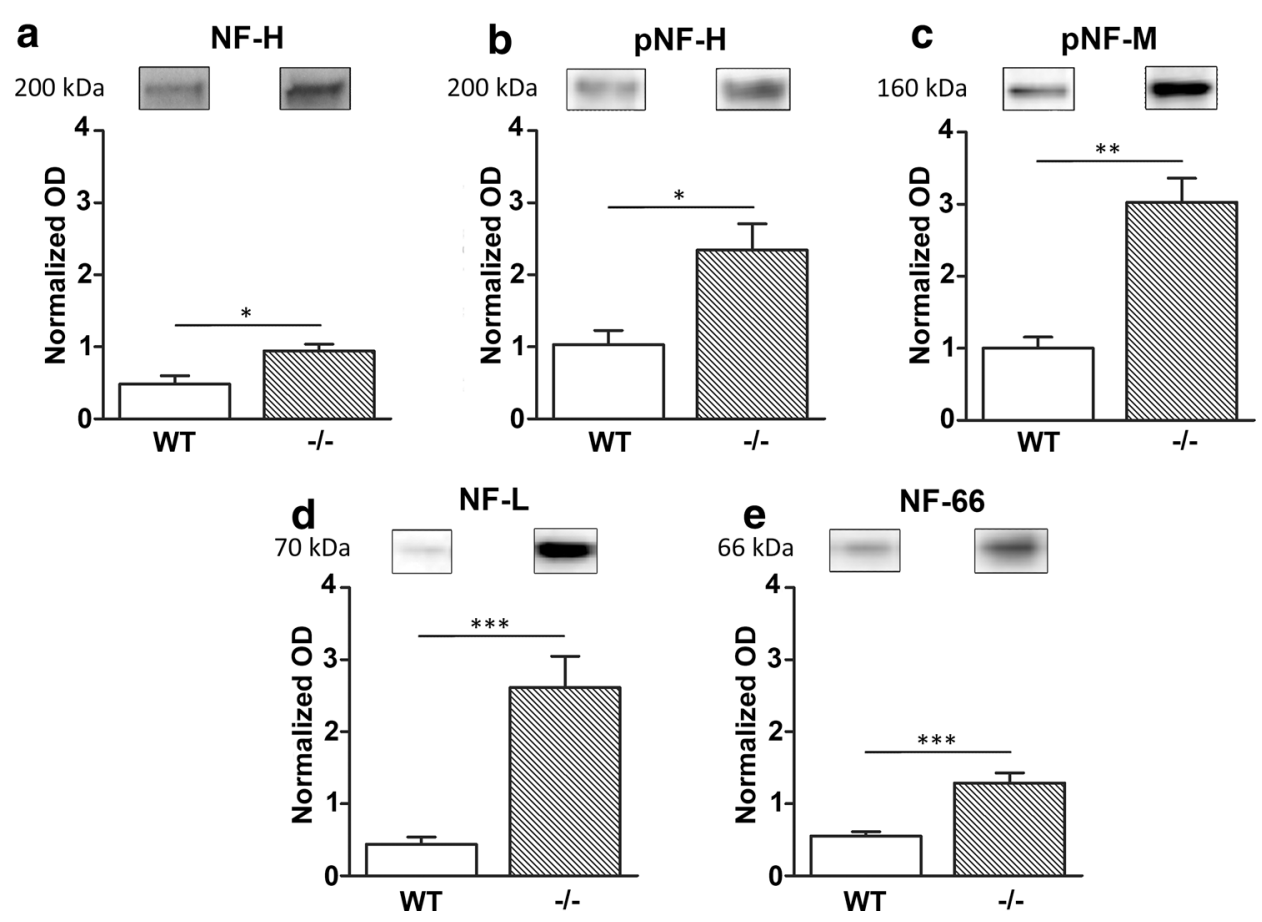

structural appearance. In more detail, layer V pyramidal cells of $\mathrm{MMP}-3^{-/-}$mice displayed significantly shorter apical dendrites and more apical obliques per unit of length, providing one explanation for the truncated translaminar appearance of the Golgi-stained MMP- $3^{-1-}$ cortex. Consistent with our results, recent work by Van Hove et al. (2011) showed a reduced dendritic tree size of cerebellar Purkinje cells in MMP- $3^{-1-}$ mice compared with WT, both at P12 and P90. This study clearly revealed that genetic inactivation of MMP-3 has profound effects on brain development with a neuronal phenotype that persists into adulthood.

The exact mechanism by which MMP-3 mediates the abnormal dendritic arborization remains elusive but MMPdependent activation of neurotrophins provides an attractive mechanism. Several neurotrophins and growth factors such as insulin-like growth factor-1 (IGF-1) are known to not only influence dendritic outgrowth but also to play a role in visual cortex plasticity (McAllister et al. 1995; Niblock et al. 2000; Lodovichi et al. 2000; Maya-Vetencourt et al. 2012). They might therefore be suggested as putative MMP-3 targets mediating the observed phenotype. All known mammalian neurotrophins act as major regulatory signals in the lamina-specific development of apical and basal dendrites in the visual cortex of the mouse (McAllister et al. 1995). Specifically, brain-derived neurotrophic factor (BDNF), a known substrate of MMP-3 (Lee et al. 2001; Milward et al. 2007) regulates the growth and branching of layer $\mathrm{V}$ pyramidal cells in the visual cortex (McAllister et al. 1995). Nerve growth factor has similar effects as BDNF on dendritic arborization and regulates MMP-3 expression (Nordstrom et al. 1995) and can be activated by MMP-7 (Lee et al. 2001), itself an in vitro substrate of MMP-3 (McCawley and Matrisian 2001).

Other alternative mechanisms might involve MMPmediated integrin (Schulze-Tanzil et al. 2001) and semaphorin signaling (Gonthier et al. 2006). Several MMPs can be linked to integrin-mediated signaling pathways by interaction with ECM molecules (Schulze-Tanzil et al. 2001; Wang et al. 2008; Michaluk et al. 2009) and genetic ablation of integrin-mediated signaling results in postdevelopmental, progressive retraction of dendritic arbors of layer $\mathrm{V}$ pyramidal neurons in the somatosensory and visual cortex of the mouse (Moresco 2005; Fujioka et al. 2012). On the other hand, a functional link between MMPs and guidance molecules, including semaphorins, has previously been established (McFarlane 2003). Specifically, MMP-3 is required for semaphorin-3C-dependent cortical axon outgrowth and is negatively regulated by the axonal growth inhibitory semaphorin-3A (Gonthier et al. 2006). Besides having effect on axons, class 3 semaphorins regulate dendritic growth and branching (Jan and Jan 2003; Fenstermaker et al. 2004; $\mathrm{Ng}$ et al. 2013). Alternatively, MMP-3 may be implicated in sculpting dendritic architecture by regulating the bio-availability of insulin-like growth factor1 (IGF-1) through selective cleavage of IGF-binding protein-3 (Fowlkes 2003; Milward et al. 2007) and IGF-1 is crucial for apical dendritic growth in layer II pyramidal neurons (Niblock et al. 2000). 
a
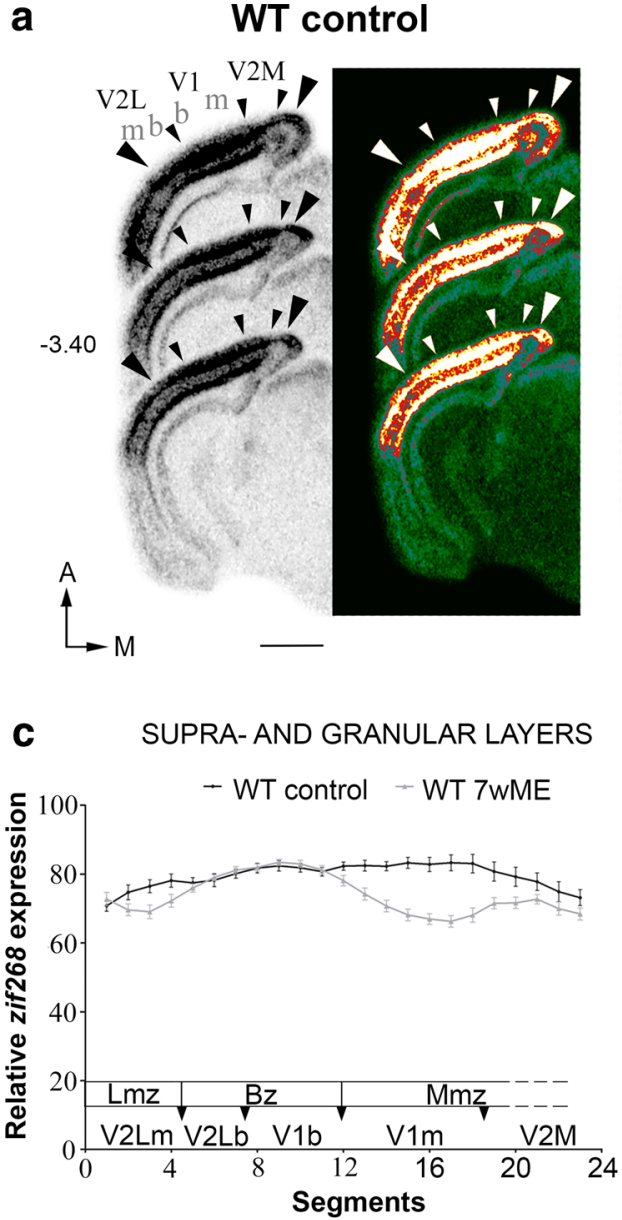

Fig. 4 Zif268 expression in the visual cortex of WT control (a) and WT mice enucleated for 7 weeks (b) reveals different reactivation patterns. For both conditions images of the left visual cortex from three adjacent sections around Bregma level $-3.40 \mathrm{~mm}$ are shown. The corresponding pseudo-color representations of signal intensity differences are displayed next to each triplet of ISH sections. The medio-lateral extent of the visual cortex is marked by the two large arrowheads and inter-areal boundaries with smaller arrowheads, as identified in the histologically processed slices (Nissl, see methods). Line graphs (c, d) illustrate the relative zif268 expression for the upper (LII-LIV) (c) and lower (LV-VI) (d) layers along the five predefined visual subdivisions (black arrowheads), corresponding with the small arrowheads in the images of $\mathbf{a}$ and $\mathbf{b}$ as measured by the average optical density in each segment, using a custom-made

MMPs regulate dendritic spine development and dynamics

It has been previously established that MMPs are expressed in dendritic spines (Konopacki et al. 2007) and are necessary for dendritic spine maturation and actin dynamics by phosphorylation of cofilin through $\beta 1$-integrin-dependent signaling (Wang et al. 2008; Dityatev et al. 2010; Conant et al. 2010) or by directly cleaving the actin filamentsevering protein gelsolin and other cytoskeletal proteins
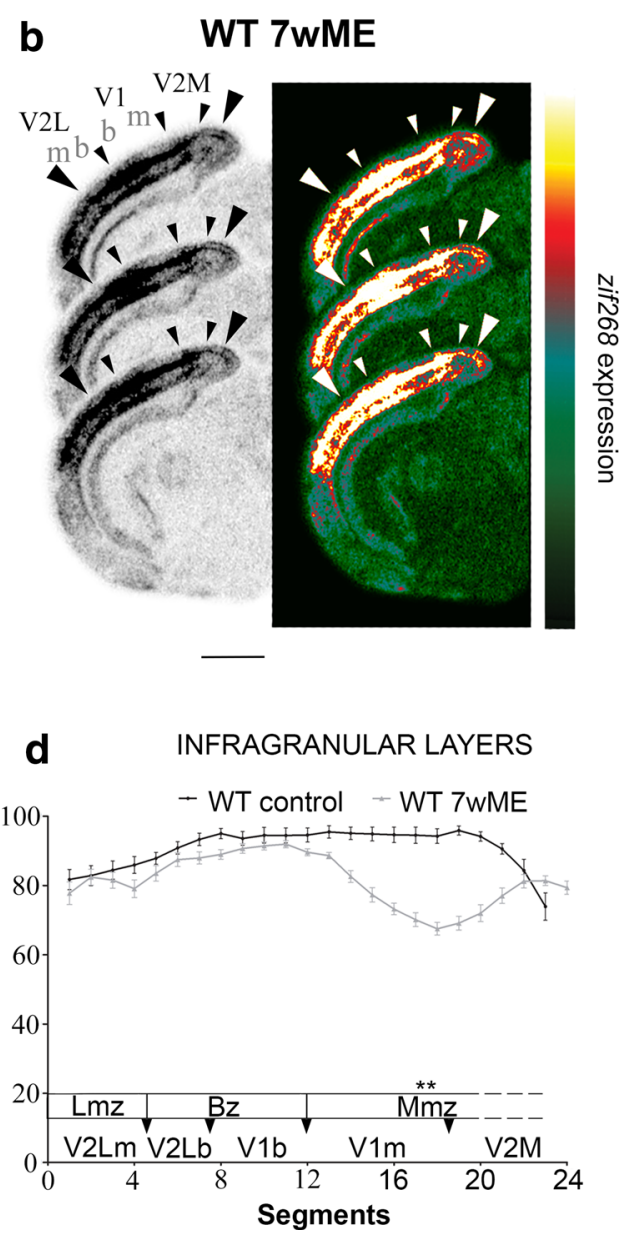

MATLAB script, for controls (black lines) and 7wME (gray lines) animals. In WT 7wME, the subregion-specific activity profiles do not differ from WT control levels except for the medial monocular zone in the infragranular layer, interpreted as evidence for visual and crossmodal reactivation. Error bars represent the SEM of the mean optical density in each segment. Statistics with $* P<0.05$, $* * P<0.01$, $* * * P<0.001$. Abbreviations: $A$, anterior; $P$, posterior; $M$, medial; $L$, lateral; $V 2 M$, medial extrastriate cortex; $V 1 m$, monocular primary visual cortex; $V 1 b$, binocular primary visual cortex; $V 2 L b$, binocular lateral extrastriate cortex; $V 2 \mathrm{Lm}$, monocular lateral extrastriate cortex; $L m z$, lateral monocular zone; $B z$, binocular zone; $M m z$, medial monocular zone; $m$, monocular; $b$, binocular; $M E$, monocular enucleation; $w$, weeks. Scale bars $2 \mathrm{~mm}$

(Vicente-Manzanares et al. 2009; Cauwe and Opdenakker 2010). Indeed, we observed a significant shift in dendritic spine length distribution towards shorter spines in MMP$3^{-1-}$ mice, indicating a role for this metalloproteinase in spinogenesis and spine maturation. Earlier studies on dendritic spines and MMPs revealed that inhibition of MMPs by minocycline induces spine maturation in cultured hippocampal neurons (Bilousova et al. 2008) while in contrast, elevated activity of MMP-7 and MMP-9 increases spine lengthening in vitro and in vivo, respectively 
a

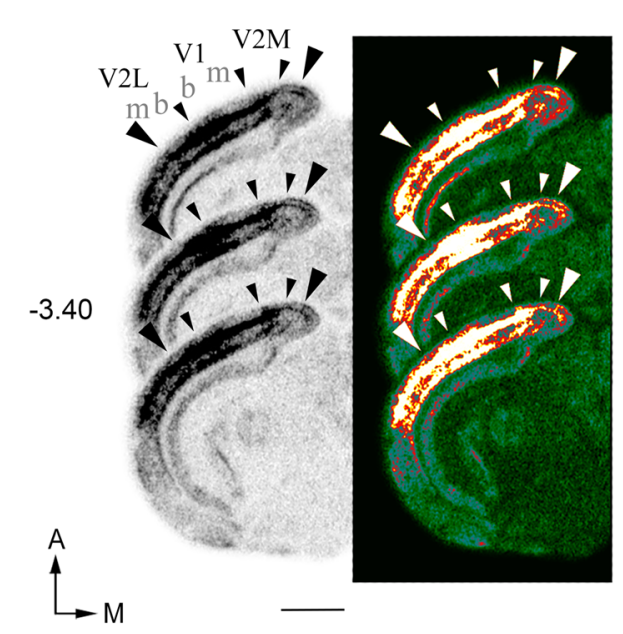

C SUPRA- AND GRANULAR LAYERS

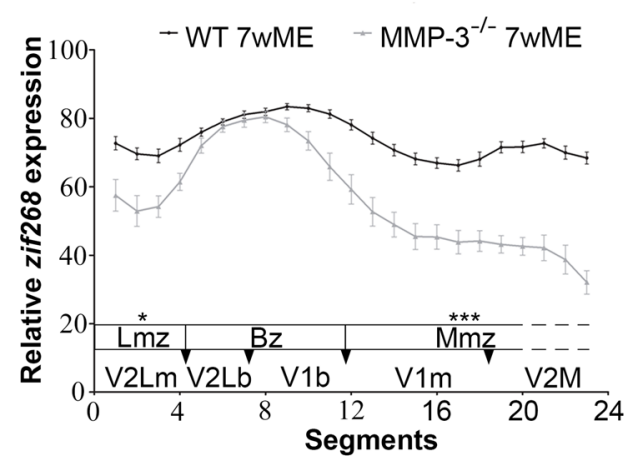

Fig. 5 Zif268 expression in the visual cortex of WT (a) and MMP$3^{-1-}$ (b) mice 7 weeks post-enucleation reveals different reactivation patterns. For both conditions images of the left visual cortex from three adjacent sections around Bregma level $-3.40 \mathrm{~mm}$ are shown. The corresponding pseudo-color representations of signal intensity differences are displayed next to each triplet of ISH sections. The medio-lateral extent of the visual cortex is marked by the two large arrowheads and inter-areal boundaries with smaller arrowheads, as identified in the histologically processed slices (Nissl, see methods). Line graphs (c, d) illustrate the relative zif268 expression for the upper (LII-LIV, c) and lower (LV-VI, d) layers along the predefined visual subdivisions (black arrowheads, corresponding with the small arrowheads in the images of $\mathbf{a}$ and $\mathbf{b}$ ) as measured by the average optical density in each segment, using a custom-made MATLAB

(Bilousova et al. 2006; Ethell and Ethell 2007; Michaluk et al. 2011). Since MMP-9 can be activated by MMP-3 (Ogata et al. 1992; McCawley and Matrisian 2001) and MMP- $3^{-1-}$ mice are characterized by a reduced pro-MMP9 activation in vivo (Johnson et al. 2011), it is conceivable that a reduced MMP-9 activity is responsible for the observed shift in spine length distribution towards shorter, more mature spines. Whether MMP-3 is an efficient activator of MMP-7 in vivo is still a matter of debate ( $\mathrm{Ra}$ and Parks 2007), making it more difficult to attribute the observed dendritic spine phenotype to a reduced activity of MMP-7. Also, a recent study by Spolidoro et al. (2012)

\section{b $\quad \mathrm{MMP}^{-3^{-/-}} \mathrm{TWME}$}

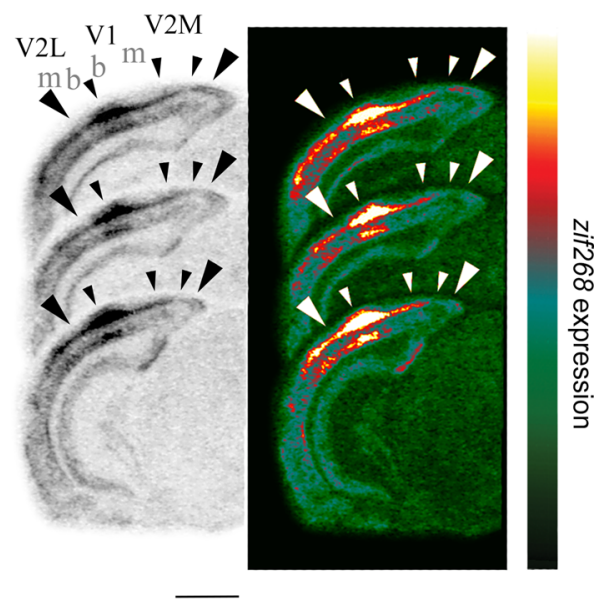

d INFRAGRANULAR LAYERS

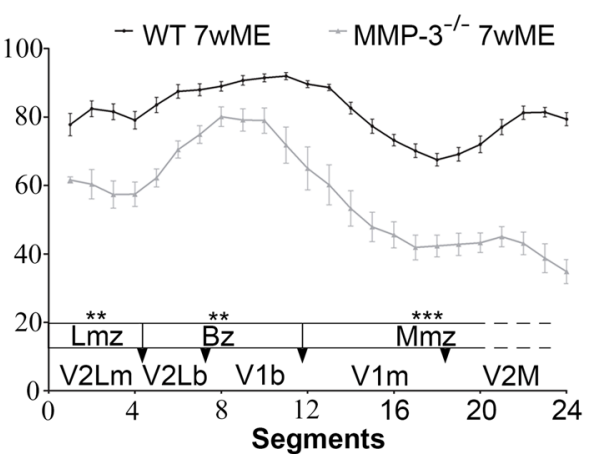

script, for WT (black lines) and MMP- $3^{-1-}$ (gray lines) animals. A lack of cross-modal plasticity in MMP- $3^{-1-}$ mice 7 weeks postenucleation is clearly visible as evidenced by the remarkable decrease in zif 268 expression in all monocular driven areas. Open-eye potentiation in these animals seems perturbed since the zif268 pattern does not expand into V1m and V2Lm. Error bars represent the SEM of the mean optical density in each segment. Statistics with $* P<0.05, * * P<0.01, * * * P<0.001$. Abbreviations: $A$, anterior; $P$, posterior; $M$, medial; $L$, lateral; $V 2 M$, medial extrastriate cortex; $V 1 m$, monocular primary visual cortex; $V 1 b$, binocular primary visual cortex; $V 2 L b$, binocular lateral extrastriate cortex; $V 2 L m$, monocular lateral extrastriate cortex; $L m z$, lateral monocular zone; $B z$, binocular zone; $M m z$, medial monocular zone; $m$, monocular; $b$, binocular; $M E$, monocular enucleation; $w$, weeks. Scale bars $2 \mathrm{~mm}$

demonstrated that MMP inhibition prevented the increase in immature spines in the visual cortex of juvenile rats after 7 days of monocular deprivation (MD) (Spolidoro et al. 2012), substantiating MMP-mediated structural plasticity in the visual system.

\section{Neurofilament protein upregulation}

The observed aberrant dendritic morphology of MMP- $3^{-/-}$ pyramidal neurons is indicative for abnormal cytoskeletal dynamics. Hence, we wanted to discern the contribution of neurofilament proteins (NF) to this phenotype since they 
constitute the major components of the neuronal cytoskeleton. Surprisingly, when comparing the NF content in the visual cortex of WT and MMP- $3^{-1-}$ mice, we found a significant upregulation in MMP- $3^{-1-}$ mice for $\alpha$-internexin (NF-66) and the light (NF-L), medium (NF-M) and heavy (NF-H) subunits, both phosphorylated (p) and nonphosphorylated. All analyzed subunits displayed a different degree of upregulation, ranging from 1.9-fold (NF-H) to 5.9-fold (NF-L), suggesting an overall change in NF subunit stoichiometry in MMP- $3^{-1-}$ mice. A normal NF subunit stoichiometry is essential for proper NF assembly and transport and alterations in stoichiometry have been implicated in several neurodegenerative diseases (Janmey et al. 2003; Lariviere and Julien 2003; Barry et al. 2007; Szaro and Strong 2010; Kim et al. 2011). Kong et al. (1998) revealed that by transgenic overexpression of different neurofilament subunits, an increased ratio of NF-H and/or NF-M to NF-L inhibited dendritic arborization in spinal motor neurons. An imbalance in the ratio of different NF subunits can alter NF assembly properties and slow down NF transport into neuronal processes which is likely to cause structural changes in dendrites (Kong et al. 1998; Barry et al. 2007; De Vos et al. 2008). In addition, increased phosphorylation of NF-H and NF-M subunits can cause slower NF transport potentially by preventing attachment to molecular motors (Barry et al. 2007; De Vos et al. 2008; Dale and Garcia 2012).

Genetic removal of MMP-3 abolishes cross-modal plasticity and perturbs open-eye potentiation

Since the MMP family has recently been implicated in visual cortex plasticity (Spolidoro et al. 2012), we here probed for cross-modal plasticity in $\mathrm{MMP}-3^{-1-}$ mice by means of the long-term monocular enucleation (ME) paradigm (Van Brussel et al. 2011; Nys et al. 2014). The zif268 activity profile of WT-enucleated mice (WT 7wME, Fig. 4) revealed a nearly full reactivation along the entire medio-lateral visual cortex thereby resembling zif268 expression levels in WT control animals with only a slight decrease in activity in the infragranular layer of the medial monocular zone (Fig. 4d). These results are consistent with previous data obtained in adult $\mathrm{C} 57 \mathrm{Bl} / 6 \mathrm{~J}$ mice (Van Brussel et al. 2011; Nys et al. 2014) and indicate that the different genetic background of our WT mice compared to $\mathrm{C} 57 \mathrm{~B} 1 / 6 \mathrm{~J}$ has a negligible effect on the cortical plasticity phenomena studied here (Heimel et al. 2008). In contrast, the lack of cross-modal reactivation in adult $\mathrm{MMP}-3^{-1-}$ mice 7wME (Fig. 5) is most likely a result of the truncated translaminar organization described above. Since pyramidal neurons in the visual cortex are essential for intra-areal and inter-areal information processing (Douglas and Martin 2004; Spruston 2008; Iurilli et al. 2012), the dendritic phenotype observed in MMP- $3^{-/-}$likely disrupts the intraareal and inherently the cortico-cortical framework necessary for cross-modal plasticity (Paperna and Malach 1991; Van Brussel et al. 2011; Nys et al. 2014). Besides the apparent absence of cross-modal plasticity, open-eye potentiation seemed perturbed as well. Indeed, the zif 268 pattern remained confined to the binocular zone and did not expand into the monocular regions as expected based on previous publications (Faguet et al. 2008; Datwani et al. 2009; Kanold et al. 2009; Nys et al. 2014). Furthermore, the permanently decreased zif268 expression in the infragranular layer of the binocular zone also supports this interpretation of an altered open-eye potentiation.

General MMP inhibition was recently reported to selectively prevent the potentiation of the open-eye after 7 days of MD in the visual cortex of juvenile rats (Spolidoro et al. 2012). This experience-dependent potentiation is necessary for a complete OD shift (Sawtell et al. 2003; Frenkel and Bear 2004) and ME induces robust OD plasticity driven by the remaining eye (Datwani et al. 2009; Kanold et al. 2009). Considerable molecular data have been obtained from classic MD experiments. In that regard, it is established that several neurotrophins, which are substrates of MMPs, modulate the outcome of MD (Maffei et al. 1992; Bonhoeffer 1996; Lodovichi et al. 2000) where administration of NGF or BDNF disrupts OD plasticity (Lodovichi et al. 2000). Moreover, BDNF is critically involved in the induction of long-term potentiation (LTP) in dendrites and spines (Kovalchuk 2002). Although MMP-3 is necessary for activation of these neurotrophins, genetic inactivation of MMP-3 likely induces complex degradomic cascades (Overall and Kleifeld 2006; Butler and Overall 2009) including compensatory upregulation of other redundant MMPs that can activate these neurotrophins (Esparza et al. 2004; Ethell and Ethell 2007). Furthermore, it is known that MMP-9, a putative downstream target of MMP-3 is necessary to maintain LTP and is upregulated by synaptic activity (Nagy et al. 2006; Huntley 2012; Wiera et al. 2012).

Classic OD plasticity cannot be explained solely by homosynaptic mechanisms (Bartoletti et al. 2002; Hensch 2005). Homeostatic plasticity has been suggested to also play a role (Desai et al. 2002; Mrsic-Flogel et al. 2007; Kaneko et al. 2008). Accordingly, tumor necrosis factor- $\alpha$ (TNF- $\alpha$ )-deficient mice lack the open-eye response typical for MD which has been attributed to perturbed homeostatic synaptic scaling (Kaneko et al. 2008). Pro-TNF- $\alpha$ is activated by several MMPs, including MMP-3 (Gearing et al. 1995; Sternlicht and Werb 2001) so the lack of MMP-3 can therefore perturb the response of the remaining eye possibly via TNF- $\alpha$. However, general MMP inhibition did not alter homeostatic plasticity in the primary visual cortex of juvenile rats following 7 days of MD (Spolidoro et al. 2012). Taken together, it is conceivable that lack of 
MMP-3 and the resulting degradome disrupts this experience-dependent potentiation process, contributing to the observed phenotype.

\section{Conclusions}

Genetic inactivation of MMP-3 clearly has profound effects on the structural and functional integrity of the visual cortex of adult mice. MMP-3 is necessary to constitute a normal phenotype of layer $\mathrm{V}$ pyramidal neurons since genetic ablation of this enzyme severely impacts apical dendritic length, branching and spine length. In addition, we revealed an aberrant cortical plasticity phenotype characterized by a perturbed open-eye potentiation and lack of cross-modally driven reactivation. Most likely this is the result from the apparent truncated translaminar cortical organization that disrupts the intra-areal and cortico-cortical communication needed for experiencedependent plasticity in combination with the perturbed set of MMP-3 substrates. To our knowledge, this is the first study that reports NF protein upregulation in an MMP deficiency model. Further experiments are needed to elucidate whether or not MMPs can directly interact with NF proteins to modulate cytoskeletal dynamics and which molecular mediators constitute the observed phenotype.

Acknowledgments We gratefully thank Ria Vanlaer and Lieve Geenen for excellent technical assistance. Jeroen Aerts is supported by a Ph.D. fellowship of the Agency for Innovation through Science and Technology Flanders (IWT Vlaanderen). This work is supported by the Fund for Scientific Research-Flanders (FWO Vlaanderen).

\section{References}

Aerts J, Nys J, Arckens L (2014) A highly reproducible and straightforward method to perform in vivo monocular enucleation in the mouse. J Vis Exp (in press)

Aldridge GM, Podrebarac DM, Greenough WT, Weiler IJ (2008) The use of total protein stains as loading controls: an alternative to high-abundance single-protein controls in semi-quantitative immunoblotting. J Neurosci Methods 172:250-254. doi:10. 1016/j.jneumeth.2008.05.003

Arckens L, Zhang F, Vanduffel W, Mailleux P, Vanderhaeghen JJ, Orban GA, Vandesande F (1995) Localization of the two protein kinase $\mathrm{C}$ beta-mRNA subtypes in cat visual system. J Chem Neuroanat 8:117-124

Arckens L, Van der Gucht E, Eysel UT, Orban GA, Vandesande F (2000) Investigation of cortical reorganization in area 17 and nine extrastriate visual areas through the detection of changes in immediate early gene expression as induced by retinal lesions. J Comp Neurol 425:531-544

Barry DM, Millecamps S, Julien J-P, Garcia ML (2007) New movements in neurofilament transport, turnover and disease. Exp Cell Res 313:2110-2120. doi:10.1016/j.yexcr.2007.03.011

Bartoletti A, Cancedda L, Reid SW, Tessarollo L, Porciatti V, Pizzorusso T, Maffei L (2002) Heterozygous knock-out mice for brain-derived neurotrophic factor show a pathway-specific impairment of long-term potentiation but normal critical period for monocular deprivation. J Neurosci 22:10072-10077

Bilousova TV, Rusakov DA, Ethell DW, Ethell IM (2006) Matrix metalloproteinase-7 disrupts dendritic spines in hippocampal neurons through NMDA receptor activation. J Neurochem 97:44-56. doi:10.1111/j.1471-4159.2006.03701.x

Bilousova TV, Dansie L, Ngo M, Aye J, Charles JR, Ethell DW, Ethell IM (2008) Minocycline promotes dendritic spine maturation and improves behavioural performance in the fragile $\mathrm{X}$ mouse model. J Med Genet 46:94-102. doi:10.1136/jmg.2008. 061796

Birdal T (2011) Smoothing 2D contours using local regression lines. MATLAB central file exchange

Bonhoeffer T (1996) Neurotrophins and activity-dependent development of the neocortex. Curr Opin Neurobiol 6:119-126

Butler GS, Overall CM (2009) Updated biological roles for matrix metalloproteinases and new "Intracellular" substrates revealed by degradomics. Biochemistry 48:10830-10845. doi:10.1021/ bi901656f

Cauwe B, Opdenakker G (2010) Intracellular substrate cleavage: a novel dimension in the biochemistry, biology and pathology of matrix metalloproteinases. Crit Rev Biochem Mol Biol 45:351-423. doi: 10.3109/10409238.2010.501783

Cnops L, Hu T-T, Vanden Broeck J, Burnat K, Van den Bergh G, Arckens L (2007) Age- and experience-dependent expression of Dynamin I and Synaptotagmin I in cat visual system. J Comp Neurol 504:254-264. doi:10.1002/cne.21415

Conant K, Wang Y, Szklarczyk A, Dudak A, Mattson MP, Lim ST (2010) Matrix metalloproteinase-dependent shedding of intercellular adhesion molecule- 5 occurs with long-term potentiation. Neurosci 166:508-521. doi:10.1016/j.neuroscience.2009.12.061

D'Errico J (2012) Interparc. MATLAB central file exchange

Dale JM, Garcia ML (2012) Neurofilament phosphorylation during development and disease: which came first, the phosphorylation or the accumulation? J Amino Acids 2012:1-10. doi:10.1007/ s00401-011-0848-5

Datwani A, McConnell MJ, Kanold PO, Micheva KD, Busse B, Shamloo M, Smith SJ, Shatz CJ (2009) Classical MHCI molecules regulate retinogeniculate refinement and limit ocular dominance plasticity. Neuron 64:463-470. doi:10.1016/j.neuron. 2009.10.015

De Vos KJ, Grierson AJ, Ackerley S, Miller CCJ (2008) Role of axonal transport in neurodegenerative diseases*. Annu Rev Neurosci 31:151-173. doi:10.1146/annurev.neuro.31.061307. 090711

Desai NS, Cudmore RH, Nelson SB, Turrigiano GG (2002) Critical periods for experience-dependent synaptic scaling in visual cortex. Nat Neurosci 5:783-789. doi:10.1038/nn878

Dityatev A, Schachner M, Sonderegger P (2010) The dual role of the extracellular matrix in synaptic plasticity and homeostasis. Nat Rev Neurosci 11:735-746. doi:10.1038/nrn2898

Douglas RJ, Martin KAC (2004) Neuronal circuits of the neocortex. Annu Rev Neurosci 27:419-451. doi:10.1146/annurev.neuro.27. 070203.144152

Dziembowska M, Wlodarczyk J (2012) MMP9: a novel function in synaptic plasticity. Int J Biochem Cell Biol 44:709-713. doi:10. 1016/j.biocel.2012.01.023

Esparza J, Kruse M, Lee J, Michaud M, Madri JA (2004) MMP-2 null mice exhibit an early onset and severe experimental autoimmune encephalomyelitis due to an increase in MMP-9 expression and activity. FASEB J 18:1682-1691. doi:10.1096/ fj. $04-2445 \mathrm{com}$

Ethell IM, Ethell DW (2007) Matrix metalloproteinases in brain development and remodeling: synaptic functions and targets. J Neurosci Res 85:2813-2823. doi:10.1002/jnr.21273 
Faguet J, Maranhao B, Smith SL, Trachtenberg JT (2008) Ipsilateral eye cortical maps are uniquely sensitive to binocular plasticity. J Neurophysiol 101:855-861. doi:10.1152/jn. 90893.2008

Fenstermaker V, Chen Y, Ghosh A, Yuste R (2004) Regulation of dendritic length and branching by semaphorin 3A. J Neurobiol 58:403-412. doi:10.1002/neu.10304

Fowlkes JL (2003) Regulation of insulin-like growth factor (IGF)-I action by matrix metalloproteinase- 3 involves selective disruption of IGF-I/IGF-binding protein-3 complexes. Endocrinology 145:620-626. doi:10.1210/en.2003-0636

Franklin K, Paxinos G (2008) The mouse brain in stereotaxic coordinates, 3rd edn. Elsevier, Amsterdam

Frenkel MY, Bear MF (2004) How monocular deprivation shifts ocular dominance in visual cortex of young mice. Neuron 44:917-923. doi:10.1016/j.neuron.2004.12.003

Fujioka H, Dairyo Y, Yasunaga K-I, Emoto K (2012) Neural functions of matrix metalloproteinases: plasticity, neurogenesis, and DISEASE. Biochem Res Int 2012:1-8. doi:10.1016/j. neuron.2010.06.021

Gearing AJ, Beckett P, Christodoulou M, Churchill M, Clements JM, Crimmin M, Davidson AH, Drummond AH, Galloway WA, Gilbert R (1995) Matrix metalloproteinases and processing of pro-TNF-alpha. J Leukoc Biol 57:774-777

Gonthier B, Nasarre C, Roth L, Perraut M, Thomasset N, Roussel G, Aunis D, Bagnard D (2006) Functional interaction between matrix metalloproteinase-3 and semaphorin-3C during cortical axonal growth and guidance. Cereb Cortex 17:1712-1721. doi:10.1093/cercor/bhl082

Gonthier B, Koncina E, Satkauskas S, Perraut M, Roussel G, Aunis D, Kapfhammer JP, Bagnard D (2009) A PKC-dependent recruitment of MMP-2 controls semaphorin-3A growth-promoting effect in cortical dendrites. PLoS One 4:e5099. doi:10.1371/ journal.pone.0005099.s001

Heimel JA, Hermans JM, Sommeijer JP, Neuro-Bsik Mouse Phenomics consortium, Levelt CN (2008) Genetic control of experience-dependent plasticity in the visual cortex. Genes Brain Behav 7:915-923. doi:10.1111/j.1601-183X.2008.00431.x

Hensch TK (2005) Critical period plasticity in local cortical circuits. Nat Rev Neurosci 6:877-888. doi:10.1038/nrn1787

Hinkle CL, Diestel S, Lieberman J, Maness PF (2006) Metalloprotease-induced ectodomain shedding of neural cell adhesion molecule (NCAM). J Neurobiol 66:1378-1395. doi:10.1002/neu. 20257

Hu T-T, Van den Bergh G, Thorrez L, Heylen K, Eysel UT, Arckens L (2011) Recovery from retinal lesions: molecular plasticity mechanisms in visual cortex far beyond the deprived zone. Cereb Cortex 21:2883-2892. doi:10.1093/cercor/bhr079

Huntley GW (2012) Synaptic circuit remodelling by matrix metalloproteinases in health and disease. Nat Rev Neurosci 13:743-757. doi:10.1038/nrn3320

Irwin SA, Idupulapati M, Gilbert ME, Harris JB, Chakravarti AB, Rogers EJ, Crisostomo RA, Larsen BP, Mehta A, Alcantara CJ, Patel B, Swain RA, Weiler IJ, Oostra BA, Greenough WT (2002) Dendritic spine and dendritic field characteristics of layer $\mathrm{V}$ pyramidal neurons in the visual cortex of fragile-X knockout mice. Am J Med Genet 111:140-146. doi:10.1002/ajmg.10500

Iurilli G, Ghezzi D, Olcese U, Lassi G, Nazzaro C, Tonini R, Tucci V, Benfenati F, Medini P (2012) Sound-driven synaptic inhibition in primary visual cortex. Neuron 73:814-828. doi:10.1016/j. neuron.2011.12.026

Jan Y-N, Jan LY (2003) The control of dendrite development. Neuron 40:229-242

Janmey PA, Leterrier J-F, Herrmann H (2003) Assembly and structure of neurofilaments. Curr Opin Colloid Int 8:40-47. doi:10.1016/S1359-0294(03)00010-4
Johnson JL, Dwivedi A, Somerville M, George SJ, Newby AC (2011) Matrix metalloproteinase (MMP)-3 activates MMP-9 mediated vascular smooth muscle cell migration and neointima formation in mice. Arterioscler Thromb Vasc Biol 31:e35-e44. doi:10. 1161/ATVBAHA.111.225623

Kaczmarek L, Chaudhuri A (1997) Sensory regulation of immediateearly gene expression in mammalian visual cortex: implications for functional mapping and neural plasticity. Brain Res Rev 23:237-256

Kaneko M, Stellwagen D, Malenka RC, Stryker MP (2008) Tumor necrosis factor- $\alpha$ mediates one component of competitive, experience-dependent plasticity in developing visual cortex. Neuron 58:673-680. doi:10.1016/j.neuron.2008.04.023

Kanold PO, Kim YA, GrandPre T, Shatz CJ (2009) Co-regulation of ocular dominance plasticity and NMDA receptor subunit expression in glutamic acid decarboxylase-65 knock-out mice. J Physiol 587:2857-2867. doi:10.1113/jphysiol.2009.171215

Kim S, Chang R, Teunissen C, Gebremichael Y, Petzold A (2011) Neurofilament stoichiometry simulations during neurodegeneration suggest a remarkable self-sufficient and stable in vivo protein structure. J Neurol Sci 307:132-138. doi:10.1016/j.jns. 2011.04.023

Kong J, Tung VW-Y, Aghajanian J, Xu Z (1998) Antagonistic roles of neurofilament subunits NF-H and NF-M against NF-L in shaping dendritic arborization in spinal motor neurons. J Cell Biol 140:1167-1176

Konopacki FA, Rylski M, Wilczek E, Amborska R, Detka D, Kaczmarek L, Wilczynski GM (2007) Synaptic localization of seizure-induced matrix metalloproteinase-9 mRNA. Neurosci 150:31-39. doi:10.1016/j.neuroscience.2007.08.026

Kovalchuk Y (2002) Postsynaptic induction of BDNF-mediated longterm potentiation. Science 295:1729-1734. doi:10.1126/science. 1067766

Lariviere RC, Julien J-P (2003) Functions of intermediate filaments in neuronal development and disease. J Neurobiol 58:131-148. doi:10.1002/neu.10270

Lee R, Kermani P, Teng KK, Hempstead BL (2001) Regulation of cell survival by secreted proneurotrophins. Science 294:1945-1948. doi:10.1126/science.1065057

Lodovichi C, Berardi N, Pizzorusso T, Maffei L (2000) Effects of neurotrophins on cortical plasticity: same or different? J Neurosci 20:2155-2165

Maffei L, Berardi N, Domenici L, Parisi V, Pizzorusso T (1992) Nerve growth factor (NGF) prevents the shift in ocular dominance distribution of visual cortical neurons in monocularly deprived rats. J Neurosci 12:4651-4662

Mannello F, Medda V (2012) Nuclear localization of matrix metalloproteinases. Prog Histochem Cytochem 47:27-58. doi:10.1016/j.proghi.2011.12.002

Maya-Vetencourt JF, Baroncelli L, Viegi A, Tiraboschi E, Castren E, Cattaneo A, Maffei L (2012) IGF-1 restores visual cortex plasticity in adult life by reducing local GABA levels. Neural Plast 2012:1-10. doi:10.1038/nn1860

McAllister AK, Lo DC, Katz LC (1995) Neurotrophins regulate dendritic growth in developing visual cortex. Neuron 15:791803

McCawley LJ, Matrisian LM (2001) Matrix metalloproteinases: they're not just for matrix anymore! Curr Opin Cell Biol 13:534-540

McFarlane S (2003) Metalloproteases: carving out a role in axon guidance. Neuron 37:559-562

Meighan SE, Meighan PC, Choudhury P, Davis CJ, Olson ML, Zornes PA, Wright JW, Harding JW (2006) Effects of extracellular matrix-degrading proteases matrix metalloproteinases 3 and 9 on spatial learning and synaptic plasticity. J Neurochem 96:1227-1241. doi:10.1111/j.1471-4159.2005.03565.x 
Michaluk P, Mikasova L, Groc L, Frischknecht R, Choquet D, Kaczmarek L (2009) Matrix metalloproteinase-9 controls NMDA receptor surface diffusion through integrin 1 signaling. J Neurosci 29:6007-6012. doi:10.1523/JNEUROSCI.5346-08. 2009

Michaluk P, Wawrzyniak M, Alot P, Szczot M, Wyrembek P, Mercik K, Medvedev N, Wilczek E, De Roo M, Zuschratter W, Muller D, Wilczynski GM, Mozrzymas JW, Stewart MG, Kaczmarek L, Wlodarczyk J (2011) Influence of matrix metalloproteinase MMP-9 on dendritic spine morphology. J Cell Sci 124:3369-3380. doi:10.1242/jcs.090852

Milward EA, Fitzsimmons C, Szklarczyk A, Conant K (2007) The matrix metalloproteinases and CNS plasticity: an overview. J Neuroimmunol 187:9-19. doi:10.1016/j.jneuroim.2007.04.010

Moresco EMY (2005) Integrin-mediated dendrite branch maintenance requires abelson (Abl) family kinases. J Neurosci 25:6105-6118. doi:10.1523/JNEUROSCI.1432-05.2005

Mrsic-Flogel TD, Hofer SB, Ohki K, Reid RC, Bonhoeffer T, Hübener M (2007) Homeostatic regulation of eye-specific responses in visual cortex during ocular dominance plasticity. Neuron 54:961-972. doi:10.1016/j.neuron.2007.05.028

Murphy G, Stanton H, Cowell S, Butler G, Knäuper V, Atkinson S, Gavrilovic J (1999) Mechanisms for pro matrix metalloproteinase activation. APMIS 107:38-44

Nagy V, Bozdagi O, Matynia A, Balcerzyk M, Okulski P, Dzwonek J, Costa RM, Silva AJ, Kaczmarek L, Huntley GW (2006) Matrix metalloproteinase-9 is required for hippocampal late-phase longterm potentiation and memory. J Neurosci 26:1923-1934. doi:10.1523/JNEUROSCI.4359-05.2006

Ng T, Ryu JR, Sohn JH, Tan T, Song H, Ming G-L, Goh ELK (2013) Class 3 semaphorin mediates dendrite growth in adult newborn neurons through Cdk5/FAK pathway. PLoS One 8:e65572. doi:10.1371/journal.pone.0065572.s003

Niblock MM, Brunso-Bechtold JK, Riddle DR (2000) Insulin-like growth factor I stimulates dendritic growth in primary somatosensory cortex. J Neurosci 20:4165-4176

Nordstrom LA, Lochner J, Yeung W, Ciment G (1995) The metalloproteinase stromelysin-1 (transin) mediates PC12 cell growth cone invasiveness through basal laminae. Mol Cell Neurosci 6:56-68

Nys J, Aerts J, Ytebrouck E, Vreysen S, Laeremans A, Arckens L (2014) The cross-modal aspect of mouse visual cortex plasticity induced by monocular enucleation is age dependent. J Comp Neurol 522:950-970. doi:10.1002/cne.23455

Ogata Y, Enghild JJ, Nagase H (1992) Matrix metalloproteinase 3 (stromelysin) activates the precursor for the human matrix metalloproteinase 9. J Biol Chem 267:3581-3584

Oliveira-Silva P, Jurgilas PB, Trindade P, Campello-Costa P, Perales J, Savino W, Serfaty CA (2007) Matrix metalloproteinase-9 is involved in the development and plasticity of retinotectal projections in rats. Neuroimmunomodulation 14:144-149

Overall CM, Kleifeld O (2006) Tumour microenvironment-opinion: validating matrix metalloproteinases as drug targets and antitargets for cancer therapy. Nat Rev Cancer 6:227-239. doi:10. $1038 / \mathrm{nrc} 1821$

Paperna T, Malach R (1991) Patterns of sensory intermodality relationships in the cerebral cortex of the rat. J Comp Neurol 308:432-456. doi:10.1002/cne.903080310

Paulussen M, Jacobs S, Gucht E, Hof PR, Arckens L (2011) Cytoarchitecture of the mouse neocortex revealed by the lowmolecular-weight neurofilament protein subunit. Brain Struct Funct 216:183-199. doi:10.1007/s00429-011-0311-3

Penn AA, Shatz CJ (1999) Brain waves and brain wiring: the role of endogenous and sensory-driven neural activity in development. Pediatr Res 45:447-458. doi:10.1203/00006450-19990401000001
Ra H-J, Parks WC (2007) Control of matrix metalloproteinase catalytic activity. Matrix Biol 26:587-596

Sawtell NB, Frenkel MY, Philpot BD, Nakazawa K, Tonegawa S, Bear MF (2003) NMDA receptor-dependent ocular dominance plasticity in adult visual cortex. Neuron 38:977-985. doi:10. 1016/S0896-6273(03)00323-4

Schulze-Tanzil G, de Souza P, Merker HJ, Shakibaei M (2001) Colocalization of integrins and matrix metalloproteinases in the extracellular matrix of chondrocyte cultures. Histol Histopathol $16: 1081$

Solé S, Petegnief V, Gorina R, Chamorro A, Planas AM (2004) Activation of matrix metalloproteinase- 3 and agrin cleavage in cerebral ischemia/reperfusion. J Neuropathol Exp Neurol 63:338-349

Spolidoro M, Sale A, Berardi N, Maffei L (2008) Plasticity in the adult brain: lessons from the visual system. Exp Brain Res 192:335-341. doi:10.1007/s00221-008-1509-3

Spolidoro M, Putignano E, Munafo C, Maffei L, Pizzorusso T (2012) Inhibition of matrix metalloproteinases prevents the potentiation of nondeprived-eye responses after monocular deprivation in juvenile rats. Cereb Cortex 22:725-734. doi:10.1093/cercor/ bhr158

Spruston N (2008) Pyramidal neurons: dendritic structure and synaptic integration. Nat Rev Neurosci 9:206-221. doi:10. 1038/nrn2286

Sternberger LA, Sternberger NH (1983) Monoclonal antibodies distinguish phosphorylated and nonphosphorylated forms of neurofilaments in situ. Proc Natl Acad Sci USA 80:6126-6130

Sternlicht MD, Werb Z (2001) How matrix metalloproteinases regulate cell behavior. Annu Rev Cell Dev Biol 17:463-516

Szaro BG, Strong MJ (2010) Post-transcriptional control of neurofilaments: new roles in development, regeneration and neurodegenerative disease. Trends Neurosci 33:27-37. doi:10.1016/j. tins.2009.10.002

Szklarczyk A, Lapinska J, Rylski M, McKay RDG, Kaczmarek L (2002) Matrix metalloproteinase-9 undergoes expression and activation during dendritic remodeling in adult hippocampus. J Neurosci 22:920-930

Van Brussel L, Gerits A, Arckens L (2009) Identification and localization of functional subdivisions in the visual cortex of the adult mouse. J Comp Neurol 514:107-116. doi:10.1002/cne. 21994

Van Brussel L, Gerits A, Arckens L (2011) Evidence for cross-modal plasticity in adult mouse visual cortex following monocular enucleation. Cereb Cortex 21:2133-2146. doi:10.1093/cercor/ bhq 286

Van der Gucht E, Hof PR, Van Brussel L, Burnat K, Arckens L (2007) Neurofilament protein and neuronal activity markers define regional architectonic parcellation in the mouse visual cortex. Cereb Cortex 17:2805-2819. doi:10.1093/cercor/bhm012

Van Hove I, Verslegers M, Buyens T, Delorme N, Lemmens K, Stroobants S, Gantois I, D'Hooge R, Moons L (2011) An aberrant cerebellar development in mice lacking matrix metalloproteinase-3. Mol Neurobiol 45:17-29. doi:10.1007/s12035-011$8215-\mathrm{z}$

Vicente-Manzanares M, Hodges J, Horwitz AR (2009) Dendritic spines: similarities with protrusions and adhesions in migrating cells. Open Neurosci J 3:87-96. doi:10.2174/18740820009 03020087

Wang X-B, Bozdagi O, Nikitczuk JS, Zhou Q, Huntley GW (2008) Extracellular proteolysis by matrix metalloproteinase-9 drives dendritic spine enlargement and long-term potentiation coordinately. Proc Natl Acad Sci 105:19520-19525

Wiera G, Wójtowicz T, Lebida K, Piotrowska A, Drulis-Fajdasz D, Gomułkiewicz A, Gendosz D, Podhorska-Okołów M, Capogna M, Wilczyński G, Dzięgiel P, Kaczmarek L, Mozrzymas JW 
(2012) Long term potentiation affects intracellular metalloproteinases activity in the mossy fiber-CA3 pathway. Mol Cell Neurosci 50:147-159. doi:10.1016/j.mcn.2012.04.005

Woolley DG, Laeremans A, Gantois I, Mantini D, Vermaercke B, Op de Beeck HP, Swinnen SP, Wenderoth N, Arckens L, D'Hooge R (2013) Homologous involvement of striatum and prefrontal cortex in rodent and human water maze learning. Proc Natl Acad Sci USA 110:3131-3136. doi:10.1073/pnas.1217832110

Worley PF, Christy BA, Nakabeppu Y, Bhat RV, Cole AJ, Baraban JM (1991) Constitutive expression of zif268 in neocortex is regulated by synaptic activity. Proc Natl Acad Sci 88:5106-5110

Wright JW, Meighan PC, Brown TE, Wiediger RV, Sorg BA, Harding JW (2009) Habituation-induced neural plasticity in the hippocampus and prefrontal cortex mediated by MMP-3. Behav Brain Res 203:27-34. doi:10.1016/j.bbr.2009.04.014
Yasunaga K-I, Kanamori T, Morikawa R, Suzuki E, Emoto K (2010) Dendrite reshaping of adult drosophila sensory neurons requires matrix metalloproteinase-mediated modification of the basement membranes. Dev Cell 18:621-632. doi:10.1016/j.devcel.2010. 02.010

Yong VW (2005) Metalloproteinases: mediators of pathology and regeneration in the CNS. Nat Rev Neurosci 6:931-944. doi:10. 1038/nrn 1807

Zangenehpour S, Chaudhuri A (2002) Differential induction and decay curves of c-fos and zif268 revealed through dual activity maps. Mol Brain Res 109:221-225 